\title{
ARE INFRASTRUCTURES IMPORTANT TO STOP RURAL DEPOPULATION?
}

\author{
Verónica Cañal Fernández y Antonio Álvarez Pinilla
}

Depto. de Economía. Universidad de Oviedo

\begin{abstract}
The aim of this article is to study the causes of rural depopulation and, particularly, the role of infrastructures. To do this we build a panel data set at the municipal level where the rural population has been defined at a very fine level of granularity. The main results show the importance of infrastructures to maintain rural population. The presence of a medium-size town in the municipality helps to fix the population in the countryside. However, the income gap with urban municipalities contributes to reduce rural population.
\end{abstract}

Keywords: Rural depopulation, Infrastructures, Municipality, Demography.

\section{Introduction}

Many studies have been devoted to studying the causes of rural depopulation (e.g., Goetz and Debertin, 1996; Liu et al., 2017). Rural depopulation in Spain has been studied in depth by Collantes and Pinilla (2011), who examine this process during the twentieth century. Urbanization and industrialization were the main drivers of the process of rural population change. Other reasons for the population decline are natural disadvantages, poor communication infrastructures, inconveniences of living in low population density areas and the relative proximity of industrial centers (Collantes and Pinilla, 2004). However, demographic developments also had their role in rural depopulation. The low birth rates made it impossible to compensate the migrations from the countryside, causing a decrease in the number of rural inhabitants. Collantes and Pinilla (2008) highlight that "Aging is a key factor in low crude birth rates and high crude death rates".

In this paper we analyze the evolution of rural population in Asturias. We have assembled a panel data set of 78 municipalities during the years 1970-2018. We make use of detailed information about each municipality's population at the 'singular entity' level, which is data collected in every population register by the Spanish Statistical Institute (INE).

Our main interest is to study the role played by played by the existence of infrastructures in the rural areas. While it is commonly argued that the lack of infrastructures is a determinant of rural depopulation, there are not many studies that have tested this hypothesis since there is usually a lack of data about physical infrastructures. Additionally, the results of the papers that have tackled this topic are inconclusive. Voss and Chi (2006) argue that "following a thorough review of the relevant literature, the notion that highway expansion leads to increased population growth in the vicinity of the improved infrastructure finds only weak and often conflicting support".

We estimate an econometric model to explain the differences in the levels of rural population across municipalities and over time. Our model uses a broad set of explanatory variables that include the economic situation of the municipality (non-agricultural production, agricultural productivity, industrial labor, urbanrural income gap), the endowment of infrastructures (hospitals, highways, education), and some characteristics of the municipality that define its life conditions (altitude, distance to the main cities of the region, presence of an important town).

\section{Data}

One of the main features of this paper is to use singular entity data to compute rural population for each municipality. Most of the explanatory variables have been provided by SADEI (Asturian Statistical Institute). The infrastructure variables, such as distances to the nearest hospital or highway, were not available and we had to build them up.

The first challenge is to define rural population. Many empirical studies use data at the municipality level and define rural municipalities as those with population below a certain threshold. For example, Huang et al. (2002) consider a county as rural if total urban population is under 20,000 and has a farm population of at least 400 . We have defined rural population based on the number of people that live in settlements below a certain threshold. For example, our variable RuralPop_2K includes the people in a municipality in a given year that live in settlements with less than two thousand people. In our empirical analysis we have considered two other variables which use higher thresholds of four and six thousand people.

We will consider in our regression model three groups of variables: 
a) Economic factors

- Importance of non-agricultural sectors: the presence of firms is expected to reduce the need to migrate. For this reason, we include the percent of gross value added in the non-agricultural sectors as an indicator of the capacity of the municipality to absorb labor (NONAGPROD).

- Profitability of agriculture: agricultural and livestock activities are the main economic activities in rural areas. If these activities are profitable, the incentive to leave is smaller. As an indicator of profitability, we include the gross value added per worker in this sector (AGPRODUCTIVITY).

- Employment in the industrial sector: one of the main reasons to leave a rural area is the lack of employment. Industrial jobs are preferred to the service sector since they are seen as more stable and the average wage is higher. For this reason, we include the percent of industrial workers in the labor force (INDUSTRIALLABOR).

- Income Gap. Even if the economic situation in the rural municipality is good in absolute terms, people tend to compare with the situation in other places. In this sense, it has been widely recognized that the income gap between urban and rural areas is a main driver of depopulation (e.g., San Juan and Suyer, 2019). We have used the difference between net family income in the capital of the region and in each municipality (INCOMEGAP).

b) Infrastructures: we consider that the probability of migration decreases with the presence of good infrastructures. While many types of infrastructures can be taken into account, we consider two elements of social infrastructure (hospitals and schools) as well as highways.

- Distance to the nearest hospital: since there are just a few big hospitals in the region, we do not measure the presence of this infrastructure since most municipalities do not have one. Instead, we measure the distance from the capital of the municipality to the nearest hospital in terms of time (TIMEHOSPITAL). ${ }^{22}$

- Distance to the nearest highway: highways improve the connectivity of rural areas helping to reduce travel time. Therefore, we expect that the farther the nearest highway, the higher the probability of leaving the municipality. This variable was not available in the public statistics and we had to construct it. Since it takes a while to build highways, especially in regions with sloppy landscape such as Asturias, new highways are put into service by pieces, which made it difficult to compute a measure of distance to a highway. Following Baum-Snow (2007) we measure this variable as the distance in kilometers to the connecting point of the nearest highway (DISTHIGHWAY).

- Educational infrastructures: we have chosen two educational levels in the Spanish education system: the existence of primary schools and high schools in the municipality as indicators of educational infrastructures. These variables have been created from the Official Register of Educational Centers, taking into account the years in which the schools opened, closed or merged. In the empirical model we have used binary variables $(1=$ yes, $0=$ no) to measure the presence in the municipality of at least one primary school (PRIMARYSCHOOL) and one high school (HIGHSCHOOL).

c) Municipality characteristics

- Altitude: people tend to move to areas with good weather. We consider the altitude of the municipality capital in meters (ALTITUDE).

- Distance to a "big" city: Living far from an urban center has been considered one of the main determinants of rural depopulation. We have considered a city as "big" if it holds more than 40,000 people and measured the minimum of the distances in $\mathrm{km}$ to them (DISTBIGCITY).

- Urbanization. the presence or urban areas reduces the need to migrate. We have included a binary variable that takes value 1 if there is at least one town with more than 10,000 people in the municipality (CITY10K).

- Agricultural structure: the agricultural sector differs across municipalities. We believe that dairy farming creates a higher link to the territory than other types of farms. We represent the farming structure as the percent of dairy farms over all livestock farms (DAIRYFARMING).

\section{Estimation and results}

Our empirical model is the following:

$$
\begin{aligned}
& L_{-} Y_{i t}=\alpha+\beta_{1} L_{-} \text {Size }_{i}+\beta_{2} P_{-} \text {NonAgProd }_{i t}+\beta_{3} L_{-} \text {AgProductivity } \text { Prt }_{5}+\beta_{4} P_{-} \text {Industrial Labor }_{i t}+ \\
& \beta_{5} \text { IncomeGap }_{i t}+\beta_{6} L_{-} \text {TimeHospital }_{i t}+\beta_{7} L_{-} \text {DistHighway }_{i t}+\beta_{8} \text { B_PrimarySchool }_{i t}+ \\
& \beta_{9} B_{-} \text {HighSchool }_{i t}+\beta_{10} L_{-} \text {Altitude }_{i}+\beta_{11} L_{-} \text {DistBigCity }{ }_{i}+ \\
& +\beta_{12} B_{-} \text {City } 10 K_{i t}+\beta_{13} P_{-} \text {DairyFarming } i t+\beta_{14} \text { Trend }_{t}+\varepsilon_{i t}
\end{aligned}
$$

\footnotetext{
22 The computation of distances (in kilometers or time) was done using Google Maps taking into account the type of road existing at each moment (in particular, the existence of highways).
} 
where subscript $i$ indicates municipality and subscript $t$ represents time. The dependent variable and most of the continuous independent variables are in logs, as indicated by an ' $\mathrm{L}_{-}$'. The 'B_' and ' $\mathrm{P}_{-}$' stand for binary and proportion, respectively. The estimation of equation (2) by Ordinary Least Squares for the three dependent variables described previously is displayed in Table 1.

Table 1. Estimation of the population equation

\begin{tabular}{|c|c|c|c|c|c|c|}
\hline & \multicolumn{2}{|c|}{ Rural Population $<2000$} & \multicolumn{2}{|c|}{ Rural Population $<4000$} & \multicolumn{2}{|c|}{ Rural Population $<6000$} \\
\hline & Coef. & t-ratio & Coef. & t-ratio & Coef. & t-ratio \\
\hline Constant & $5.845 * * *$ & 46.17 & $5.679 * * *$ & 42.50 & $6.140 * * *$ & 55.66 \\
\hline L_Size & $0.693 * * *$ & 25.27 & $0.685 * * *$ & 23.47 & $0.425 * * *$ & 31.69 \\
\hline P_NonAgProd & $0.600 * * *$ & 6.42 & $0.843 * * *$ & 9.14 & $0.977 * * *$ & 13.01 \\
\hline L_AgProductivity & 0.032 & 1.16 & $0.065 * *$ & 2.10 & $0.038 *$ & 1.71 \\
\hline P_IndustrialLabor & $0.198 * * *$ & 7.20 & $0.108 * * *$ & 4.07 & $0.049 * *$ & 2.04 \\
\hline IncomeGap & $-0.088 * * *$ & -6.36 & $-0.146 * * *$ & -10.21 & $-0.212 * * *$ & -18.17 \\
\hline L_TimeHospital & $-0.158 * * *$ & -14.91 & $-0.208 * * *$ & -21.55 & $-0.183 * * *$ & -18.62 \\
\hline L_DistHighway & $-0.065 * * *$ & -7.91 & $-0.040 * * *$ & -4.69 & $-0.014 *$ & -1.82 \\
\hline B_PrimarySchool & $0.422 * * *$ & 14.02 & $0.412 * * *$ & 13.44 & $0.549 * * *$ & 22.31 \\
\hline B_HighSchool & $0.092 * *$ & -2.27 & 0.035 & 0.80 & $0.527 * * *$ & 23.86 \\
\hline L_Altitude & $-0.045 * * *$ & -6.02 & $-0.060 * * *$ & -7.39 & $-0.044 * * *$ & -7.41 \\
\hline L_DistBigCity & $-0.100 * * *$ & -8.64 & $-0.044 * * *$ & -3.80 & $-0.032 * * *$ & -2.98 \\
\hline B_City10K & $0.349 * * *$ & 13.10 & $0.333 * * *$ & 11.50 & $0.162 * * *$ & 5.56 \\
\hline P_DairyFarming & $0.761 * * *$ & 23.71 & $0.823 * * *$ & 25.42 & $0.732 * * *$ & 23.68 \\
\hline Trend & $-0.008 * * *$ & -5.10 & $-0.007 * * *$ & -4.27 & $-0.005^{* * *}$ & -4.01 \\
\hline $\mathrm{R}^{2}$ & $79 \%$ & & $80 \%$ & & $87 \%$ & \\
\hline Observations & 3,354 & & 3,354 & & 3,354 & \\
\hline
\end{tabular}

$*, * *, * * *$ indicate statistical significance at the $10 \%, 5 \%$ and $1 \%$ significance levels.

The first three economic variables are positive and significant. As expected, a larger share of production in sectors other than agriculture, higher agricultural productivity, and more weight of industrial employment all increase rural population. Therefore, population stays in rural areas where the economic situation is favorable. The negative sign of IncomeGap, on the other hand, indicates that the higher the difference between local income and income in urban areas (as measured by the income in the capital of the region), the lower the rural population.

The infrastructure variables also carry the expected sign. The further the distance to the nearest hospital, the lower the rural population. The effect of the binary variables that measures the existence of primary and high schools in the municipality is positive. This result suggests that the policy of rural school closures has probably had a negative effect on rural population. In Spain, as many other countries the continuous decline in rural school enrolment led to a process of closures and amalgamation that resulted in an increase in commuting time for many young scholars.

The distance to a highway is negative and significant in the three models, indicating that the further away the connection to a highway, the lower the rural population. Our finding that the proximity of highways helps to retain population contributes to a scant literature on the effect of highways on rural population change. Chi used data at the minor civil division level (a sub-county level) in Wisconsin to investigate the effects of highway improvements on population change, finding that in rural areas, highway improvement promotes population growth. A similar result was obtained by Alama-Sabater et al. (2019), who study the factors that condition rural depopulation using data at the municipality level in Valencia finding that lack of accessibility of rural locations is a sufficient condition for high depopulation risk.

With regards to the characteristics of the municipalities, the coefficient of the altitude of the capital is always negative and significant, reflecting the well-known fact that people tend to move away from mountainous areas and locate in lowland or coastal destinations. Collantes and Pinilla (2004) have studied this phenomenon for the Spanish mountainous municipalities. The distance to a big city (over 40,000 
people) is also negative and significant, as expected. This is a very important variable in depopulation studies. Dijkstra and Poelman (2008) found that 'remote rural regions' are the only group with a negative population growth in the EU-27.

An important explanatory variable is the presence in the municipality of a town larger than 10,000 people, which is measured by the binary variable CITY10K. The positive coefficient on this variable indicates that these towns help to maintain the population in the countryside.

\section{Summary and Conclusions}

We examine the evolution of population in the rural areas of Asturias. Rural population was computed using three different thresholds, two, four and six thousand people. The three variables show a decreasing trend during the period 1970-2018, but there are significant differences across municipalities, with just a few gaining rural population.

What can be done to stop population decline in rural areas? The results of our econometric model point to some well-known drivers. First of all, the economic soundness of the rural municipalities helps to reduce population decline, although the income gap with urban municipalities contributes to reduce the rural population. Second, proximity to social and physical infrastructures is also an important factor to keeping population in rural areas. Third, the presence of a medium-size city in the municipality (in our case, larger than 10,000 inhabitants) plays an important role in keeping rural population in the countryside.

In summary, policymakers should seriously consider if costly investments in infrastructures (proximity to hospitals, schools, highways...) are necessary to keep population in the rural areas of the region.

\section{References}

Alamá-Sabater, L., Budí, V., García Álvarez-Coque, J.M. and Roig-Tierno, N. (2019). "Using mixed research approaches to understand rural depopulation”. Economía Agraria y Recursos Naturales, 19(1): 99-120.

Baum-Snow, N. (2007). "Did highways cause suburbanization?". The Quarterly Journal of Economics, 122(2): 775-805.

Chi, G. (2012). "The Impacts of Transport Accessibility on Population Change across Rural, Suburban and Urban Areas: A Case Study of Wisconsin at Sub-county Levels". Urban Studies, 49(12): 27112731.

Collantes, F. and Pinilla, V. (2004). "Extreme Depopulation in the Spanish Rural Mountain Areas: A case study in Aragon in the 19th and 20th centuries". Rural History, 15(2): 149-166.

Collantes, F. and Pinilla, V. (2011). Peaceful Surrender: The Depopulation of Rural Spain in the Twentieth Century. Newcastle-upon-Tyne, Cambridge Scholars Publishing.

Dijkstra, L. and Poelman, H. (2008). Remote rural regions: How proximity to a city influences the performance of rural regions. Regional Focus 1/2008. EC-DG REGIO, Brussels.

Goetz, S. and Debertin, D. (1996). "Rural Population Decline in the 1980s: Impacts of Farm Structure and Federal Farm Programs". American Journal of Agricultural Economics, 78: 517-529.

Huang, T., Orazem, P., and Wohlgemuth, D. (2002). "Rural Population Growth, 1950-1990: The Roles of Human Capital, Industry Structure and Government Policy". American Journal of Agricultural Economics, 84(3): 615-627.

Liu, Z., Liu, S., Jin, H. and Qi, W. (2017). "Rural population change in China: Spatial differences, driving forces and policy implications". Journal of Rural Studies, 51: 189-197.

Pinilla, V., Ayuda, M. and Sáez, L. (2008). "Rural depopulation and the migration turnaround in Mediterranean western Europe: A case study of Aragon". Journal of Rural and Community Development, 3(1): 1-22.

San Juan, C. and Suñer, C. (2019). "Rural Depopulation and Income Convergence". Economía Agraria y Recursos Naturales, 19(2): 29-48.

Voss, P.R. and Chi, G. (2006). "Highways and Population Change". Rural Sociology, 71(1): 33-58. 